\title{
Welcome to Double Helix
}

Seattle has its double helix pedestrian bridge. The Fermi National Accelerator Laboratory (Fermilab) outside Chicago has its gold-colored double helix staircase within the Proton Pagoda. Construction has even begun on a double helix skyscraper in Taipei, Taiwan. And as Robert Smart chronicles in "Double Helix: History and Origins," scholar-teacher Ann E. Berthoff's metaphoric musing on the double helix is the genesis for this journal's name. Thus, it is both fitting and felicitous that the inaugural issue of Double Helix: A Journal of Critical Thinking and Writing should launch in the $60^{\text {th }}$ anniversary year of Watson and Crick's discovery of the molecular structure of DNA.

Double Helix seeks to attract a global readership for the purpose of sharing research and best practices in the use of writing to develop critical thinking skills and disciplinary expertise in higher education. We are interested in advancing the extraordinary work of Writing Across the Curriculum (WAC) and Writing In the Disciplines (WID) ongoing in the United States, as well as highlighting and promoting transferable pedagogies and research interests with appeal well beyond the U.S. Furthermore, we are hopeful that the open access, online venue that makes research freely available to scholars, teachers, and students across the globe will serve to support a wider exchange of knowledge, as well as international and interdisciplinary collaboration.

This first issue includes work that stems from Quinnipiac University's 2012 Fourth Biennial Conference on Critical Thinking and Writing, "New Vistas: WAC/WID Intersections in the $21^{\text {st }}$ Century." While we include work that deals explicitly with programs and institutional policies germane primarily to the U.S., we have also chosen pieces that focus more broadly on pedagogical issues that fell within the scope of the conference yet also pertain to policies and practices international in scope. Our desire is that this first issue signals our commitment to include important work from all who are exploring the thinking-writing connection. And now for a glimpse into that work.

Employing an institutional theory framework, Cathleen Erwin and Tina Zappile analyze the response of an interdisciplinary department to a 2008 university-wide WID initiative that emphasized "the connection between writing and critical thinking." As a result of three identified institutional pressures-normative, mimetic, and coercive--they report "significant positive change in the inclusion of writing" in each of the undergraduate programs studied. Notable in this study is that the catalyst for change comes from the top, a university task force arguing for increasing the writing and critical thinking skills of graduates. In addition to awareness of the influences on faculty in the face of such an initiative, they conclude that "empowering faculty members is key to a successful writing initiative."

Nicole Glen examines how preservice elementary teachers use "argumentative writing," meaning Toulmin's "claims, data (evidence), and warrants (reasons)," both in the classroom as well as in their own science notebooks. Of particular interest is the stated need, based upon her two-year study, that teachers "understand the connections between what learning looks like in science and how that can be accomplished through writing." Note that learning happens through writing, and that this looks different than the more traditionally understood paradigm for assessing learning, particularly in STEM classes, in which writing shows or demonstrates end-product learning. She then analyzes a key potential benefit of writing scientific arguments in the elementary classroom, namely, that students will be learning and reinforcing writing practices that are part of the K-5 Common Core State Standards (CCSS) for English Language Arts. 
Understanding that effective reading is essential for critical thinking, and that together writing and reading form a "single act of literacy," Academic Specialist Tracy Hallstead and I join forces to address problems that both instructors and Learning Commons specialists have observed with incoming freshman students and reading. We outline four common barriers to effective reading in the disciplines-the tendency to discount the importance of reading, focusing on details and task completion rather than discerning the "big picture," a faulty reliance on memory that results in commonplaces, and lack of persistence in completing difficult texts. Innovative strategies to break down these barriers include moderately difficult problem-solving techniques, metacognitive practices to enhance understanding, the privileging of story, and utilizing WAC principles in the design of both reading and writing assignments.

Given the program philosophy that "highlights writing as a problem solving activity that takes on highly specialized forms within disciplinary communities," Michelle LaFrance lays out the transformation of First Year English at University of Massachusetts Dartmouth, and specifically English 102, from a traditional literature-based writing course into a Writing about Writing course with a WAC approach. She then includes narratives from five instructors about their own unique approaches to the retooled English 102 as evidenced by a specific mid-course assignment designed to increase students' awareness of the complexity and situated nature of the college-level writing task and to prepare them for the shared final paper assignment, "A Guide to Writing in Your Major." Finally, Steven Corbett reviews how the program transformation and resulting metacognitive student practices serve to foster the desired "habits of mind" identified in the Framework for Success in Postsecondary Writing.

Patricia Morelli and Mary Gannotti report from the field (University of Hartford) on a collaborative teaching initiative in the Pre-Physical Therapy seminars in which physical therapy instructors paired with Rhetoric and Professional Writing instructors with the "dual goal of fostering physical therapy professionalism and improved written and oral discourse competencies." Both PT and writing faculty valued the interdisciplinary collaboration and pedagogical principles of the pilot project. The model is still in place after the two-year benchmark as a result of measurable improvement in both professional behavior and "research-driven academic discourse."

In his review of After the Public Turn: Composition, Counterpublics, and the Citizen Bricoleur by Frank Farmer, Adam Katz asks all the right questions. With a respectful nod to Farmer's account of the history and theory of public spaces, and of his proposal for the "counterpublic" in composition studies, and hence the composition classroom, Katz suggests that the very students who are not dissatisfied with their place among the citizenry "might be compelled to create their own counterpublics within the classroom," but that the key questions for Farmer's line of thinking are: "What is the benefit? In other words, what are students learning in such a class, why is it valuable that they learn it, and why in a composition class?" The caution then for the counterpublicist pedagogy is how to genuinely assess student work. Finally, Katz notes that to the extent that the "bricoleur" is "thrown back upon his or her own resources and forced to make meaning out of the materials at hand," the disciplinary classroom-peopled by whatever stripe of "counterpublicist"--serves to incite dialogue among fellow inquirers and invites writing to inspire. Not a bad aspiration, that.

In her review of Who Speaks for Writing: Stewardship in Writing Studies in the $21^{\text {st }}$ Century, Kat Gonso suggests that this collection of essays inspired by the 2008 conference of the same name "is less a solid answer to [Doug] Hesse's question than a testament to the power behind it." The focus of the essays 
moves from writing in institutional contexts to the multi-faceted term "stewardship" to concerns of the classroom, but Gonso observes that the "identity crisis in writing studies" referenced by many authors in this volume has become even more complex with the idea of learning transfer, which introduces additional constituents--critical thinking specialists, disciplinary practitioners, to name two--into the mix. She concludes, "The power behind stewardship in writing studies is only now beginning to be tapped."

As these contributions demonstrate, the range of voices that speak to connections between critical thinking and writing is broad indeed. And in forthcoming issues, we hope to grow this conversation even further. Just as DNA functions to provide a means to "pass on" what is critical to the growth of the organism, we envision Double Helix as a site for the ongoing transmission of theoretical, practical, and pedagogical insights into the critical thinking/writing nexus.

\section{ACKNOWLEDGEMENTS}

I wish to thank all who have contributed to bringing Double Helix to fruition. Particularly, I thank Managing Editor Paul Pasquaretta and Associate Editor Justin Hayes for their valuable insights, constant attention to detail, and great good humor throughout. I also thank our editorial team who worked cheerfully and efficiently with multiple deadlines to shepherd each piece from submission to final copyedit: Tricia Dowcett, Tracy Hallstead, Melissa Kaplan, Adam Katz, Gary Pandolfi, Jonathan Rounds, and John Ward, as well as a number of reviewers from other colleges and universities. I am also thankful for the collective wisdom of our outstanding Advisory Board--Suzanne Hudd, Neal Lerner, Sally Mitchell, and Robert Smart. Finally, I must offer heartfelt thanks and appreciation to Robert Smart, Suzanne Hudd, and Andrew Delohery, without whose years of leadership of QUWAC there would be no Double Helix.

Glenda Pritchett, Editor

Quinnipiac University 